\title{
INFORMATION TECHNOLOGY IN EDUCATIONAL MANAGEMENT AS AN EMERGING DISCIPLINE
}

\author{
ADRIE J. VISSCHER \\ University of Twente, The Netherlands
}

\begin{abstract}
This chapter introduces the application of computerized management information systems in schools and presents a brief history of the dynamic area of Information Technology in Educational Management (ITEM). Subsequently, the background of this special issue and a framework for its contents are portrayed. Finally, an overview is presented of the contents of the special issue. Copyright 101996 Elsevier Science Ltd
\end{abstract}

\section{Introduction}

The tangible advantages of computer use in terms of efficiency and effectiveness have led to the wide utilization of computer technology for the operation and management of school organizations. Information Technology in Educational Management (ITEM) is rapidly increasing in importance world-wide and is becoming an enterprise of importance in its own right. While one country may be further along than another in the status of computer application implementation, the added value of ITEM in comparison to manual modes of operation is recognized in many countries.

Computers can help school managers in finding creative solutions for complex allocation problems (e.g., teacher allocation, timetable construction) and supporting them in monitoring carefully how the school operates. School information systems (SISs) can provide managers with the information required for informed planning, policy-making, and evaluation; in addition, SISs can assist in improving the efficiency and effectiveness of schools, ITEM also occurs in the form of school office automation: electronic mail, electronic archives, spreadsheets, electronic appointment books, automatic dialing, and desk-top publishing.

This special issue deals with the design, implementation, and evaluation of computer-assisted information systems for educational organizations. Although the term "information systems" has become very popular it is not always clear what is meant by it. The concept can be used in a very broad sense referring to the information system of an organization which encompasses all formal and informal manual, computer-supported, and verbal activities directed at collecting, distributing, and processing all kinds of data within an organization. 
The more narrow and more current meaning points to computer-assisted recording, processing, and production of data. In this context, various terms are being used, for example, information systems, management information systems, and decision-support systems.

Visscher (1992, p. 65) has offered the following working definition: "an information system (IS) is based on one or more computers, consisting of a database and one or more computer applications, enabling the user to record, process, retrieve, output, and distribute data". Since the technology forming the basis of information systems is developing continuously, the contents of the "information system" concept are also always under change.

The support that an IS can provide depends on the number and type of computer applications included (e.g., student registration, financial planning, attendance registration, educational evaluation). In some cases the applications are by nature registrational; in others the assistance the system can offer is more directed to the management of an institution.

To give the reader some idea of when and how the introduction of SISs started, how the area developed, and how far schools have progressed in applying this type of technology, the history of ITEM is portrayed briefly. For more detailed information the reader is referred to Visscher (1991).

\section{A Short History of ITEM}

Teachers created the first amateurish school administrative programmes for their own schools (tailor-made systems); some years later software vendors entered this market producing their own software or adapting existing software (developed by teachers) to more professional standards. The United States was a pioneer in this field when it developed the first business applications (e.g., finance, payroll) in the 1960s. Many other countries required 15-20 more years to reach the same level of administrative computing. Some countries (especially developing ones) still await the entrance to this initial development stage due to the lack of capable professionals, finance, and a technical infrastructure. Countries who were active in this area (e.g., Hong Kong, the United Kingdom, the U.S., and the Netherlands) had initial school administrative computer applications by the end of the 1970s.

In the second stage, the expansion stage (the 1970s and 1980s), a few countries produced new applications rapidly. In this stage several loose, non-integrated clerical and administrative applications were used. The lack of integration limited the possibilities for management support since managers are interested in relationships among data. During the initiation and expansion stages the primary goal of software development was to improve the efficiency of school office activities.

The next stage, the integration stage, can be characterized by management information systems and "integration of modules". It was at this stage that the value of management information was recognized for the first time. By the mid-1980s only a few countries had progressed to this stage.

Although some countries expect to enter the stabilization stage in the near future this last stage of development is still a dream since it requires the accomplishment of the full potential of computer-assistance, complete with system refinement and maintenance. Although registrational applications have been developed in many countries, software for the support of school managers remains elusive.

In the evolution of computer-assisted school administration and management, it is interesting to note that some countries which a couple of years ago were lagging behind (e.g., Australia, 
New Zealand) have changed this situation dramatically. In fact they may now be considered countries in the forefront of implementing computerized SISs. This implies that if a nation decides to direct serious attention to automating school administration and management, and if it is able and willing to commit the required resources, it is possible to change the state of the art dramatically in just a few years.

A special project initiated by the national government, a state government, or a special project group has provided the stimulus to enter a higher development stage in a considerable number of countries. Without these projects progress is much slower. The projects have been directed toward the production of better school information systems which means increased school effectiveness and school efficiency. The desired outcome was to realize all possible registrational and management forms of computer support by analyzing information flows and information demands in schools systematically, then designing the architecture of the entire information system, and finally developing framework-modules in a stepwise manner. In the case of these special projects, systems development is not just done for a few schools, but for as many schools as possible. Although the latter implies the development of a standard system, most have tried wherever possible to build flexibility into the development of their school information system. The professional approach to system design, applied in the special projects, is not widespread at this time.

The Background of this Special Issue

In 1991 the Journal of Research on Computing in Education (JRCE) published a special issue on the state of the art of computer-assisted school administration and management (Visscher, Spuck, \& Bozeman, 1991). The special issue was meant to document, on an international level, the status of computer usage in support of school administration and management. The objective was to look at points of commonality and difference across seven countries (Austrialia, Hong Kong, Israel, Mexico, The Netherlands, United Kingdom, U.S.A.) with regard to the processes and uses of computing in school administration and management. The current status and developments in the seven countries were analyzed with respect to three major issues:

- the developmental stages through which computer-assisted school administration and management had progressed;

- the available computer applications; and

- the experiences with regard to design strategies, system qualities, factors influencing implementation, and the impact of SISs.

That the importance of ITEM has increased rapidly since that special issue is shown by the enormous sums of money invested so that educational institutions may benefit from the capability of computerized information systems to support clerical work and management activities, and ultimately improve the quality of learning and teaching. Hong Kong, for example, is investing 70 million US dollars to develop an integrated computer network linking the Education Department and more than 1,500 primary and secondary schools.

Another indication of the increased importance of ITEM is shown by the following data. During the World Conference on Computers in Education held in Sydney in 1990 only one paper was presented on the use of computers for school management purposes (Visscher, 1990). During the next World Conference held in Birmingham in 1995 a considerable number of papers on this topic was presented. More importantly, a professional group of 20 experts from ten 
different countries worked during the conference week on the production of a post-conference report addressing the development, research, and implementation topics central to the ongoing growth of ITEM and the research methods and strategies needed to generate the desired knowledge and understanding (Nolan \& Visscher, 1996). In addition, the first international conference on Information Technology in Educational Management was held in Jerusalem in 1994 with a second one to be held in Hong Kong in 1996. Thereafter, the conference will be held every two years.

Although a considerable number of computer applications supporting clerical work has been developed, in many countries there is much to be done in this area. This is even more true for applications assisting school management activities. Since the full utilization of available SISs has not been realized, investment in exploring ways that will lead to more successful systems implementation is needed (e.g., alternative design strategies generating better SISs, implementation approaches that let school staff benefit more fully of the potential of these systems).

Research into ITEM has grown considerably the last five years; thus, our knowledge about and understanding of strategies for effective design and implementation has increased. This "know-how" is important, not only because of its scientific value, but also because it helps to improve the practice of school administrative computing. As such, it enables advances to higher levels of utilization and effectiveness. This special issue documents the status of knowledge regarding ITEM and points at crucial missing information. It also serves as a point of departure for future research.

The Framework for this Special Issue

Figure 1.1 contains a conceptual model with respect to the design, implementation, and impact of computer-assisted school information systems (SISs). It constitutes the rationale for the contents of this special issue.

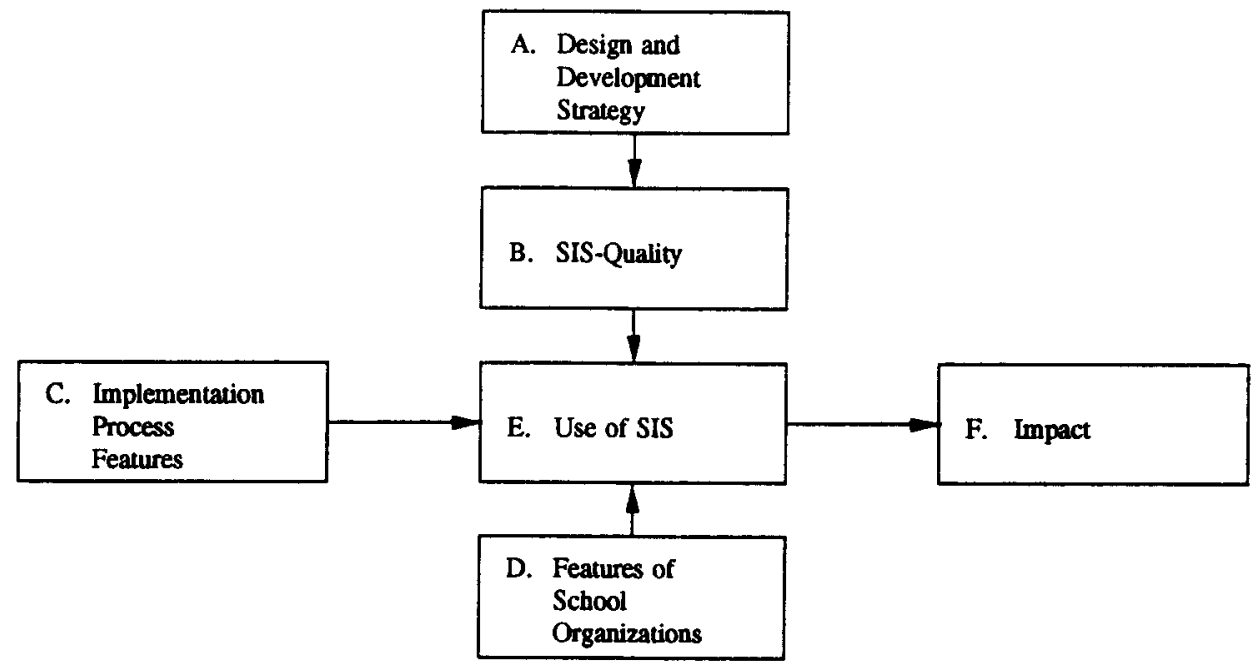

Figure 1.1. Factors determining the usage and impact of SISs. 
Figure 1.1 shows the relevant factors determining the usage and impact of SISs and their interrelationships. Because of these interrelationships, a choice in one block has consequences for what happens in one or more of the subsequent blocks. Features of the design and development strategy (Block A) influence the quality of the resulting school information system (Block B) which most probably has an impact on the magnitude of and the manner of SIS usage (Block E). Two other factors also affect the intensity and nature of system use: the features of implementation processes (Block C), and the characteristics of school organizations (Block D). System use effects (Block F) in turn are a function of the degree of use and the way in which the school information system is used.

\section{An Overview of the Chapters in this Issue}

In each of the subsequent six chapters a specific component of the framework is elaborated. The final chapter integrates the preceding chapters by observing some general patterns and problems, presenting a holistic view on the development and implementation of SISs, and discussing the dimensions of this innovation process. In addition an agenda for future ITEM-research is presented in this final chapter.

In the second chapter Fung addresses the complex issue of methodologies for designing and developing computerized school information systems. The subject of his chapter thus relates to Block $A$ in Figure 1.1. He presents the features of the methodology used in the design and development of the Hong Kong school information system and the related outcome. Moreover, he reflects on the methodology and what can be learned from its use.

Chapter 3 relates to Block B (Figure 1.1). Nolan and Ayres apply a theoretical criterion for examining the manner and sense in which the New Zealand MUSAC school information system is a "good" system in terms of design, development, and operation. In addition, research findings are presented on MUSAC acquisition and system use patterns to document the progress schools have made in realising the potential of the MUSAC system.

In Chapter 4, Visscher treats some organizational features of schools that influence system use (Block D in Figure 1.1). He first describes the various ways in which computer-assisted school information systems can support school staff (Block E). Thereafter, the results of a research review concerning the characteristics of information management at teacher and school management level are presented. Moreover, some features of school decision-making are portrayed and conclusions are drawn regarding the impact of SISs and ways in which system usage can be promoted.

In the fifth chapter a framework is developed for conceptualizing the implementation of SISs (Block C in Figure 1.1). The framework is used to examine the implementation strategies in New Zealand schools and to determine how SISs should be implemented.

In Chapter 6, Fulmer observes that little attention has been paid to training school leaders to use school information systems as decision making tools (which is an aspect of the implementation process; Block $\mathrm{C}$ in Figure 1.1). To provide a foundation for further study the purpose of Fulmer's chapter is to summarize the extant research on training administrators to use information systems.

In the seventh chapter Wild attends to how evaluation techniques can help identify and overcome the barriers to information system implementation (as such the chapter relates to both Block C and Block D in Figure 1.1). Research at Loughborough University has shown how a range of evaluation techniques can be used to assess the progress of ITEM-innovation processes 
and to overcome barriers to system success. Evaluation research, as it has been carried out until now, is reviewed with special attention paid to the User Acceptability Audit (UAA) as a special method for identifying barriers and promoting system success.

\section{References}

Nolan, P., \& Visscher, A. J. (1996). Research on application on information technology in educational management. In J. D. Tinsley \& T. J. van Weert (Eds.), Post-conference Report on the Sixth IFIP World Conference on Computers in Education (pp. 163-168). Birmingham: IFIP Technical Committee 3.

Visscher, A. J. (1990). The computer as management tool: Promises and pitfalls. In A. McDougall \& C. Dowling (Eds.), Proceedings of The Fifth World Conference on Computers in Education (pp. 609-614). Amsterdam: Elsevier Science Publisher B.V.

Visscher, A. J. (1991). School administrative computing: A framework for analysis. Journal of Research on Computing in Education, 24(1), 1-19.

Visscher, A. J. (1992). Design and evaluation of a computer-assisted information system for secondary schools. Unpublished doctoral dissertation, University of Twente, Enschede, Faculty of Educational Science and Technology. Visscher, A. J., Spuck, D. W., \& Bozeman, W. C. (Eds.) (1991). Computer-assisted school administration and management: The state of the art in seven nations. Journal of Research on Computing in Education, 24(1), 1-168. 